\title{
Hoe principieel is IFRS?
}

\section{Leo van der Tas}

SAMENVATTING In dit artikel wordt geconcludeerd dat IFRS op dit moment, welke definitie van 'principles-based standard setting' men ook hanteert, niet kunnen worden beschouwd als 'principles-based', en dat hetzelfde geldt voor US GAAP. Stilgestaan wordt bij de wenselijkheid van en randvoorwaarden voor 'principles-based standard setting'.

\section{Inleiding}

Nooit eerder in zijn geschiedenis (of die van zijn rechtsvoorganger) besteedde de International Accounting Standards Board (IASB), als verantwoordelijke organisatie voor International Financial Reporting Standards (IFRS), zo veel tijd als nu aan het nadenken over de basisprincipes onder haar eigen standaarden. Dit wordt niet alleen veroorzaakt door de op dit moment gevoerde discussie binnen de IASB omtrent de herziening van het Stramien (Framework), waarbij fundamentele vragen worden gesteld als wat is de rapporterende entiteit, op welke gebruikersbehoeften moet worden gericht, wat is een actief en wanneer is er een verplichting. Daarnaast worden in separate projecten zaken besproken als wat is reële waarde ${ }^{1}$, zijn er verschillende principes nodig voor kleine versus grote ondernemingen ${ }^{2}$ en moeten standaarden teruggebracht worden tot enkele basisprincipes met veel meer vrijheid voor de verschaffers bij het toepassen ervan? Interessant daarbij is het feit dat de IASB intern experimenteert met het ontwerpen van een 'principles-based' standaard op het terrein van leasing om te zien of dit kan werken. Eerder al had de Amerikaanse standard setter, de Financial

Prof. Dr. L(eo) G. van der Tas RA is partner vaktechniek bij Ernst \& Young Accountants en hoogleraar Externe Berichtgeving aan de Erasmus Universiteit Rotterdam.
Accounting Standards Board (FASB, 2002), een poging gewaagd om een 'principles-based standard' op te stellen. Tegen deze achtergrond wordt in deze bijdrage stilgestaan bij de vraag hoe principieel IFRS op dit moment is, hoe zich dit verhoudt tot US GAAP en welke de rol van interpretaties is bij 'principlesbased' standaarden en wat wij kunnen verwachten op het terrein van 'principles-based standard setting.'

\section{Wat zijn 'principles'?}

Een eerste voor de hand liggende vraag is wat eigenlijk bedoeld wordt met 'principles' in het kader van accounting standard setting. Een interessant overzicht van de geschiedenis van de term 'principles' in accounting vinden we in Walker (2007). Hij haalt aan dat in de dertiger jaren van de vorige eeuw de term principles gebruikt werd in de zin van conventies, afspraken en hetgeen in de praktijk als aanvaardbaar werd beschouwd (generally accepted accounting principles). Principes volgen uit observaties van de werkelijkheid. Principes waren dus niet normatief. In de zestiger jaren van de vorige eeuw krijgt het begrip 'principles' een andere betekenis. De gedachte was dat er een soort algemene waarheid was, de steen der wijzen, en dat het mogelijk was uit enkele fundamentele 'waarheden' (principles) de juiste accountingmethode, accounting practice af te leiden. Dit was niet zo zeer gestoeld op een gedachte van normativiteit, maar vanuit het idee dat, net als in de natuurwetenschappen, de wereld werd beheerst door enkele wetten van waar uit fenomenen verklaard konden worden. Dit was ook de periode waarin de FASB begon met het Conceptual Framework project dat uiteindelijk uitmondde in een serie Standards on Financial Accounting Concepts waarvan de IASC Board later zijn Framework zou afleiden. Uiteraard werden deze 'principles' tevens gebruikt voor het opstellen van standaarden die vervolgens afgedwongen werden en waaruit ook bleek dat deze 
keuzen economische consequenties hebben en dus niet waardevrij zijn (Zeff, 1978). Tegenwoordig lijken 'principles' eerder op zichzelf staande afspraken te zijn die niet noodzakelijkerwijs hoeven te zijn gebaseerd op wetenschappelijk bewezen relaties of zelfs maar op consistente veronderstellingen. Walker verzucht dan ook dat, anders dan in andere disciplines, de term 'principle' geen statement behoeft te zijn omtrent gedrag of fenomenen die (kunnen) worden ondersteund door waarnemingen of andere vormen van bewijzen. De term principles duidt eerder op een stelsel van normatieve statements die een bepaald doel van financiële verslaggeving vertegenwoordigen of een gewenst kwalitatief kenmerk van de resulterende financiële verslagen nastreven. Deze 'principles' worden soms vergezeld van uitzonderingen of beperkingen. Alexander (1999) onderscheidt 'principles' en 'rules' en binnen de principles tussen Type A en B principles. Type A principles zijn 'Overall criteria' (zoals true and fair view, de elementen van de jaarrekening en de balansbenadering versus de benadering waarbij de winst- en verliesrekening centraal staat). Bij Type B gaat het meer om conventies (afspraken) zoals het voorzichtigheidsprincipe. Een voorbeeld van 'rules' is de verplichting om bij waardering tegen kostprijs af te waarderen tot op lagere realiseerbare waarde indien zich een bijzondere waardevermindering voordoet. Nobes (2005) is het eens met deze indeling. De grens tussen 'principles and rules' wordt door Nelson (2003, p. 91) als volgt verwoord: "rules broadly... include specific criteria, 'bright lines' thresholds, examples, scope restrictions, exceptions, subsequent precedents, implementation guidance, etc. A 'standard' is the total body of principles and rules that apply to a given accounting issue". Zijn definitie van 'rules' lijkt enger te zijn dan dat van Alexander aangezien Nelson het 'lower of cost or market principle' nog als een 'principle' zou zien daar waar Alexander het als een 'rule' aanduidt.

\section{Wat betekent 'principles-based standard setting'?}

Diegenen die 'principles-based' afzetten tegen 'rulesbased' lijken te suggereren dat het voldoende is om 'principles' vast te leggen zodat 'rules' niet meer nodig zijn. In de meest extreme vorm zou het Framework dan voldoende moeten zijn voor de opsteller van een jaarrekening. Immers, de 'principles' in de betekenis die Alexander (1999) en Nobes (2005) eraan geven, zoals wat een jaarrekening is, wie de gebruikers zijn en wat een actief, een verplichting, een bate of een last is, staan beschreven in het Framework. Anderen zijn echter van mening dat 'principles-based standard setting' uitsluitend inhoudt dat elke standaard waarin meer gedetailleerde regels staan, intern consistent en consistent met de principles moet zijn. Dit streven moet er dan voor zorgen dat uitzonderingen, arbitraire grenzen en gedetailleerde richtlijnen niet of slechts beperkt meer nodig zijn. Deze zienswijze vinden we niet alleen terug bij Nobes (2005), Nelson (2003) en Schipper (2003) maar ook bij de eerste experimenten die zowel de FASB als de IASB hebben gedaan met het opstellen van een principles-based standard. De FASB (2002) deed een voorstel voor meer 'principles-based accounting standards' en illustreerde dit aan de hand van een onderdeel van FAS 133 over derivaten en FAS 34 Capitalization of Interest Cost, terwijl de IASB op dit moment intern experimenteert met een principles-based standard over leasing. In beide gevallen gaat het dus om een benadering waarbij naast het Framework meer gedetailleerde standaarden per onderwerp worden opgesteld. 'Principles-based standard setting' in de meest extreme vorm, dus het volstaan met een Framework, is in de praktijk geen haalbare kaart. Daarvoor blijft het Framework te conceptueel en is voor de toepassing in financiële verslaggeving een vertaalslag vereist van concepten naar toepassingen in de vorm van meer gedetailleerde richtlijnen. Bovendien bevat het Framework zoals wij dat op dit moment in IFRS en US GAAP kennen kwalitatieve kenmerken die tegenstrijdig zijn waardoor er een noodzaak bestaat tot het maken van keuzes tussen deze kwalitatieve kenmerken. Het andere extreem op het continuüm, de variant waarbij principles-based standard setting niet meer inhoudt dan dat alle standaarden consistent moeten zijn met de fundamentele principes van verslaggeving, lijkt onvoldoende tegemoet te komen aan de wens tot vereenvoudiging en zal niet leiden tot een grote reductie in de mate van detail van de regels. Daarmee wordt de vraag of de IASB moet gaan voor 'principles-based' of 'rules-based' standaarden een discussie omtrent nuances op een continuüm. Hoe omvangrijk en hoe gedetailleerd moeten de richtlijnen omtrent de toepassing van de principles zijn?

\section{Waarom principles-based standard setting?}

De roep om 'principles-based standard setting lijkt voor de hand te liggen. Wie kan er op tegen zijn om consistente, tot het hoogst noodzakelijke beperkte regels te laten toepassen onder toezicht van terzake kundige accountants en toezichthouders? Inderdaad zijn er belangrijke voordelen. Principles-based standards zijn eenvoudiger te begrijpen omdat zij 
duidelijk en consistent zijn, opgebouwd uit bekende principles en zonder uitzonderingen te maken. 'Principles-based standards' laten bij een goede toepassing en controle daarop minder ruimte voor misbruik. Immers, het principe voorkomt dat door middel van structurering de gewenste accounting wordt bereikt, ook al past deze niet bij de economische realiteit (ook wel aangeduid als 'substance') van de transactie. Tevens bevatten principles-based standards minder implementatierichtlijnen en interpretaties omdat dit door verminderde complexiteit en grotere consistentie niet nodig is. Ten slotte kan worden genoemd dat in een internationale omgeving waarin de IASB zich met IFRS begeeft, het eenvoudigweg onmogelijk is om zeer gedetailleerde standaarden toepasbaar te houden in een veelheid van verschillende omstandigheden, jurisdicties en bedrijfsgewoonten.

Waarom hebben we dan zoveel regels? Blijkbaar kleven er ook nadelen aan 'principles-based standard setting. Ik zal onderstaand aangeven wat in de literatuur wordt aangedragen als redenen voor het ontstaan van 'rules-based accounting standards' die dus tegelijkertijd ook de nadelen van 'principles-based standard setting' blootleggen.

- Verschillen van inzicht in wat de economische realiteit is. Hoewel het in eerste instantie voor de hand ligt om te veronderstellen dat van een transactie duidelijk is wat de economische realiteit is, kan hieromtrent een groot verschil van inzicht bestaan. Zo kan de één een lease zien als een vorm van financiering terwijl een ander een lease ziet als uitsluitend het verkrijgen van een gebruiksrecht van een actief. Bovendien bevatten veel transacties verschillende elementen waarbij het relevant kan zijn of men kijkt naar het geheel of naar de onderdelen van de betreffende transactie.

- Vergelijkbaarheid. Sommige regels worden geïntroduceerd om, hoewel arbitrair, er in elk geval voor te zorgen dat vergelijkbare transacties door alle opstellers van financiële verslagen op dezelfde wijze worden verantwoord.

- Voorkoming van misbruik. Het idee hierbij is dat elk mens geneigd is tot alle kwaad, zeker indien zich de gelegenheid voordoet. Door gedetailleerde regels kunnen gaten die in de standaarden bestaan worden gedicht en kunnen 'creatieve' interpretaties van de regels worden tegengegaan.

- Minder ruis in het communicatieproces tussen opsteller en gebruiker. Beide partijen weten waar zij aan toe zijn en komen daarmee tot een meer efficiënte uitwisseling van informatie.

- Betere controleerbaarheid van financiële verslagen met de bijbehorende reductie in rechtzaken en verminderde onzekerheid.

De ontwikkeling in de richting van 'rules-based standard setting' staat niet op zichzelf. Het kadert in een verjuridisering van de maatschappij. Op dit punt is de Verenigde Staten ons vele jaren voor en het is dan ook niet verwonderlijk dat in een meer door rechtzaken beheerste maatschappij de roep om duidelijke regels groter is. Het mag dan ook geen verbazing wekken dat US GAAP, en met name de invulling die de Securities and Exchange Commission (SEC) eraan geeft, gekenmerkt wordt door een overvloed aan zeer gedetailleerde regels. $\mathrm{Nu}$ we aan deze zijde van de oceaan al jaren een vergelijkbare tendens in de maatschappij moeten constateren, is het niet verwonderlijk dat 'rules-based standard setting' onvermijdelijk wordt. IFRS is weliswaar niet zo 'rules-based' als US GAAP, maar wordt door velen wel als 'rules-based' ervaren omdat het meer 'rulesbased' is dan de nationale standaarden waaraan men tot voor kort was gewend.

Belangrijk is te constateren dat een keuze voor 'principles-based accounting standard setting' ook nadelen heeft en dus een afweging vergt. Het is niet vanzelfsprekend dat toezichthouders bereid zullen zijn de onvermijdelijke verminderde vergelijkbaarheid te tolereren. Bovendien zal een groter beroep worden gedaan op de vakkundige oordeelsvorming en standvastigheid van zowel accountants als toezichthouders. Ter illustratie, de SEC heeft als één van de voorwaarden voor het laten vervallen van de verplichte reconciliatie van IFRS naar US GAAP voor in Amerika genoteerde buitenlandse ondernemingen gesteld dat IFRS consistent en stipt moet worden toegepast en afgedwongen. Daarbij heeft de SEC nu reeds aangegeven significante verschillen te hebben geconstateerd in de toepassing van IFRS (SEC, 2007). Hierbij moet worden aangetekend dat de SEC staff daarbij met name naar punten van presentatie en toelichting verwijst, hetgeen wellicht verklaart waarom de SEC desalniettemin het voorstel heeft gedaan om de reconciliatie tussen IFRS en US GAAP voor in de VS genoteerde niet-Amerikaanse bedrijven te laten vervallen. De zorg omtrent vergelijkbaarheid en consistentie zal alleen maar toenemen indien gedetailleerde regels worden weggenomen. Ook de gebruikers zijn niet noodzakelijkerwijs beter af. Immers, er is mogelijkerwijs sprake van verminderde vergelijkbaarheid en zal het moeilijker worden de nodige aanpassingen te maken om ondernemingen die verschillende stelsels hanteren, op één noemer te brengen. 
Een niet te onderschatten consequentie van 'principlesbased standards' voor alle betrokkenen is dat er geen of minder uitzonderingen zijn op de regels en dat resultaten meer volatiel zullen zijn vanwege het schrappen ervan (FASB, 2002, p. 8). De FASB doelt daarbij met name op het wegvallen van uitzonderingen op de scope van standaarden alsmede van afwijkingen van 'principles' door het introduceren van egalisatiemechanismen. Deze uitzonderingen en egalisatiemechanismen zijn vaak geïntroduceerd op verzoek van verschaffers of uit praktische overwegingen. De FASB noemt als nadelen van 'principlesbased standards' voorts de extra kosten en het risico dat andere partijen de ruimte die de FASB zou geven, zouden gaan invullen, met als gevolg minder duidelijkheid omtrent het geheel van regelgeving. Daarbij doelt de FASB waarschijnlijk op toezichthouders. Ten slotte wordt genoemd het risico dat de standaarden niet te goeder trouw worden toegepast, consistent met de doelstellingen ervan.

\section{Ervaringen met principles-based standard setting}

De bovengenoemde afweging roept de vraag op welke ervaringen reeds zijn opgedaan bij het opstellen van meer 'principles-based standards'. Walker (2007) doet verslag van de gevolgen die de introductie van een 'principles-based' accounting standard in Australië had op de toepassing ervan. Het betrof de introductie van een standaard omtrent de 'reporting entity', waarbij op basis van enkele algemene criteria entiteiten zelf moesten bepalen of zij een reporting entity waren in de zin van de standaard en daardoor 'general purpose financial statements' moesten opstellen. Uit het onderzoek bleek dat de introductie mislukte. Hele categorieën entiteiten die naar de geest van de standaard binnen de scope vielen, stelden geen general purpose financial statements op. Als redenen geeft Walker aan een gebrek aan toezicht door accountants en regulators. De door hem genoemde oplossingsrichtingen zijn opvallenderwijs allemaal dezelfde, namelijk meer gedetailleerde regels om misbruik te voorkomen. Een ander onderzoek, van Nelson (2003), naar de gevolgen van meer principles-based standards is een experimenteel onderzoek. Daarbij werd gekeken naar het gedrag van accountants die werden geconfronteerd met earnings management, waarbij de mate van precisie van de accounting standard werd gevarieerd. Daarbij bleek, niet verrassend, dat een meer gedetailleerde standaard tot relatief meer gevallen leidde waarbij de accountant het earnings management niet accepteerde. Echter, tevens bleek dat bij een meer gedetailleerde standaard, de accountant eerder bereid was het earnings management te accepteren indien door middel van structurering van de transactie voldaan werd aan de criteria en de gewenste accounting was bereikt, ondanks het feit dat daarmee de geest van de standaard geweld werd aangedaan. Als verklaring geeft Nelson dat de accountant in deze gevallen in elk geval de comfort heeft dat voldaan is aan de 'rule'. Als een van de oplossingen ziet Nelson de introductie van een 'true and fair view override'. De resultaten van het onderzoek illustreren empirisch het dilemma waarmee een standard setter wordt geconfronteerd. Indien we vervolgens kijken naar de pogingen die de FASB en de IASB zelf hebben gedaan om 'principlesbased' standaarden op te stellen blijkt al snel dat hiermee nog weinig vorderingen zijn gemaakt. Nadat de FASB in 2002 zijn paper schreef over 'principlesbased standard setting' is er weinig mee gedaan. Het daarin opgenomen concrete voorstel voor een vereenvoudiging van FAS 34 Capitalisation of Interest Costs is niet verder opgepakt. Opvallend is voorts dat kort na de discussie van het paper FASB Interpretation 46 over de consolidatie van special purposes entities werd gepubliceerd, waarschijnlijk een van de beste voorbeelden van een 'rules-based standard', bedoeld om misbruik van non-consolidatie van Special Purpose Entities (SPEs) te voorkomen. Niet toevallig was 2002 de periode van Enron. Ondanks het feit dat sommigen van mening zijn dat 'principles-based standards' beter in staat zijn misbruik tegen te gaan, achtten in elk geval de FASB en de SEC het blijkbaar niet het moment om detailregels op te heffen. De IASB is intern bezig met het ontwikkelen van een 'principlesbased standard' over leasing, daarbij eenvoudigweg uitgaande van het oude G4+1 discussion paper over Leasing ${ }^{3}$, om te voorkomen dat het op de inhoud zou focusen in plaats van de structuur. Dit concept is dus gebaseerd op het principe dat een gebruiksrecht een actief is en dat een verplichting om gedurende een bepaalde periode te betalen voor dat recht van gebruik een huidige verplichting is. Bij het ontwikkelen van deze dummy-standaard blijkt reeds hoe moeilijk het is om een principles-based standard te schrijven. Het is niet zo moeilijk om dit principe op te schrijven, maar wel om vervolgens de scope van de standaard goed te verwoorden alsmede de uitwerking van het principe op allerlei vormen van verlengings- en koopopties, de relatie met resultaatverantwoording op verkopen bij een sale-leaseback of van een manufacturor-lessor, enzovoort.

Geconcludeerd moet worden dat er nog weinig praktische ervaring is met 'principles-based standard setting' en dat de ervaring die is opgedaan niet ongedeeld positief is. 


\section{Is IFRS 'principles-based'?}

Zoals bovenstaand uiteengezet kan bij 'principlesbased standard setting' worden gedacht aan een set van regelgeving die uitsluitend de fundamentele beginselen vastlegt, dan wel een set van standaarden die wel in detail treden, maar niet meer dan nodig en die ook allemaal consistent zijn met de fundamentele beginselen. We kunnen al snel concluderen dat IFRS niet 'principles-based' is in de eerste betekenis. Immers, naast het Framework kent IFRS 2300 pagina's met een groot aantal standaarden, waarvan sommigen een grote mate van detail kennen. Dezelfde conclusie kan overigens worden bereikt voor US GAAP.

Nobes (2005) noemt een zestal voorbeelden van standaarden binnen IFRS (en US GAAP) die naar zijn mening niet of onvoldoende gestoeld zijn op 'principles' en daarmee onnodig arbitrair, complex en gedetailleerd zijn:

- IAS 17 Leasing is onnodig arbitrair en 'rules-based' door het maken van onderscheid tussen operating en finance leases door middel van arbitraire regels. Hetzelfde geldt voor US GAAP.

- De corridor benadering in IAS 19 Employee Benefits is niet gebaseerd op een principle, doch slechts een compromis om volatiliteit in de winst- en verliesrekening te voorkomen. Hetzelfde geldt voor US GAAP.

- IAS 39 Financial Instruments: Recognition and Measurement is niet gebaseerd op enig 'principle', bovendien speelt de intentie van het management een rol bij de wijze van verwerking van financiële instrumenten. De intentie van het management komt niet alleen nergens in het framework terug als principle, maar is ook nauwelijks te controleren en vaak zelfs bij het management niet duidelijk.

- IAS 20 Government Grants is gebaseerd op het matching principe terwijl dit principe niet (meer) in het Framework staat en daarmee dus in strijd is.

- De consolidatie van een entiteit is verplicht indien sprake is van 'control'. Onduidelijk is echter waarom potentiële stemrechten onder IFRS mee moeten worden gewogen bij de vraag of sprake is van control. Onder US GAAP wordt bij FIN 46 tevens gekeken naar de verdeling van de risico's en voordelen hetgeen weinig met 'control' te maken heeft.

- In IAS 28 Associates wordt een arbitraire grens van $20 \%$ gehanteerd als weerlegbaar vermoeden van invloed van betekenis.

De door Nobes genoemde voorbeelden kunnen gemakkelijk worden uitgebreid. Gedacht kan daarbij worden aan het feit dat IFRS een 'mixed model' kent waar het betreft waarderingsmethoden (kostprijs, reële waarde en varianten daarvan, soms binnen één standaard) de daardoor ontstane noodzaak om hedge accounting te introduceren, de vele keuzemogelijkheden tussen waarderingsmethoden in IAS 39 en de inconsistentie tussen de op matching en kostprijs gebaseerde IAS 20 enerzijds en IAS 40 Investment Property voor die bedrijven die hun onroerend goed beleggingen op reële waarde waarderen anderzijds.

De conclusie is dan ook onvermijdelijk dat IFRS evenmin voldoet aan de voorwaarden voor 'principles-based standard setting' in de tweede betekenis. Ook voor US GAAP moet worden geconstateerd dat niet voldaan wordt aan de voorwaarden. De bovengenoemde inconsistenties tussen detailregels en de algemene principes gelden net zo zeer onder US GAAP als onder IFRS. Bovendien kan US GAAP als nog meer 'rules-based' worden beschouwd dan IFRS, afgemeten aan de hoeveelheid gedetailleerde regels.

\section{Rol van disclosures}

'Principles-based standards' gaan gepaard met minder gedetailleerde regels omtrent de toepassing. Dit betekent onvermijdelijk dat ondernemingen de standaarden op verschillende wijzen gaan interpreteren. De noodzaak van het toelichten van de toepassing van de standaarden wordt daarmee groter. Jaarrekeningen worden daarmee dus niet noodzakelijkerwijs korter. De gebruiker zal willen weten op welke wijze een onderneming de standaarden heeft toegepast en hoe zich dit verhoudt tot de wijze waarop andere ondernemingen binnen de peer group dat hebben gedaan. Het is dan ook merkwaardig dat zowel in de FASB voorstellen voor een 'principlesbased standard' als in de experimentele versie van een leasing standard opgesteld door de IASB de 'disclosure' sectie niet is opgenomen. Niet uit te sluiten valt dat deze een relatief groter en belangrijker onderdeel gaat uitmaken van 'principles-based standards'.

\section{Rol van interpretaties}

Op dit moment vervullen, zowel onder IFRS als US GAAP, interpretaties een belangrijke rol. Zij zorgen er voor dat daar waar zich vragen voordoen omtrent de duiding van een standaard, het antwoord wordt gegeven in de vorm van een interpretatie. Indien er onduidelijkheid bestaat omtrent de duiding van een standaard kan dit voortvloeien uit het feit dat iets bewust niet geadresseerd is (scope exclusion) of dat een bepaalde regel strijdig is of lijkt te zijn met een elders geuit principle of met een in een andere standaard opgenomen conclusie omtrent een vergelijkbare 
situatie. Dit zijn allemaal zaken die in een 'principlesbased' omgeving niet voor zouden moeten komen. Immers, standaarden moeten altijd intern consistent, consistent met de principles en consistent met elkaar zijn zodat er ook geen plaats is voor uitzonderingen. Men zou dus verwachten dat in een wereld van 'principles-based' standaarden, interpretaties niet of toch in elk geval veel minder nodig zijn. In de uitingen van de FASB en de IASB wordt op dit punt niet ingegaan. Vastgesteld moet worden dat de IASB een veel minder belangrijke rol toekent aan interpretaties dan de FASB. Dit blijkt niet alleen uit het aantal per jaar gepubliceerde interpretaties van de International Financial Reporting Interpretations Committee (IFRIC) in vergelijking met de Abstracts van de Emerging Issues Task Force (EITF) in de VS, maar ook uit het feit dat slechts dan een interpretatie wordt uitgevaardigd, wanneer een probleem niet kan worden opgelost door een kleine wijziging van een IFRS. Zelfs dan wordt deze interpretatie zo snel mogelijk overbodig gemaakt bij de eerstvolgende belangrijke wijziging van de standaard waarop de interpretatie betrekking heeft. Onder US GAAP hebben de EITF Abstracts, FASB Interpretations, FASB Technical Bulletins en de uitspraken van SEC staff en de AICPA elk een eigen plaats in de GAAP Hierarchy en is er geen standaard beleid deze interpretaties te incorporeren in de standaarden. Geconcludeerd moet dan ook worden dat IFRS op dit punt meer 'principles-based' is dan US GAAP, maar dat ook de IASB zal moeten nadenken over de vraag of IFRIC Interpretations nog langer noodzakelijk zijn.

Het risico bestaat overigens, dat indien de FASB en de IASB niet of slechts in mindere mate interpretaties uitvaardigen en vertrouwen op het feit dat iedereen voldoende zou moeten hebben aan de principles, de behoefte aan duidelijkheid ingevuld gaat worden door interpretaties van andere organisaties dan de FASB en IASB. Dit zou dan kunnen leiden tot een wildgroei van nationale en regionale interpretaties, waardoor de doelstelling om te komen tot internationaal vergelijkbare financiële verslagen, in gevaar kan worden gebracht. Dit vereist dus discipline van nationale en regionale accounting standard setters, beroepsorganisaties en toezichthouders.

\section{De rol van derogatie}

Zowel Hoogendoorn (2004) als Ter Hoeven (2005) gaan bij het bespreken van het dilemma tussen principles-based en rules-based standard setting in op de vraag of er behoefte is aan een algemene derogatiebepaling. Op dit moment kent IFRS een derge- lijke bepaling in IAS 1, par. 17 en 18, namelijk de 'true and fair view override' volgens welke een onderneming moet afwijken van een specifieke bepaling indien toepassing van de betreffende bepaling dermate misleidend is dat dit niet kan worden opgelost door additionele toelichting. Overigens is deze bepaling met ingang van 2005 in die zin geclausuleerd dat de derogatie uitsluitend geldt indien de (lokale) relevante regelgeving toepassing ervan niet in de weg staat. Onder US GAAP is er geen expliciete bepaling die derogatie mogelijk maakt. Hoewel Hoogendoorn als ultieme oplossing ziet 'een krachtig allesoverheersend principe, waardoor gedetailleerde regels niet nodig zijn' (door hem aangeduid als middenweg 2), geeft hij in de tussentijd de voorkeur aan 'gedetailleerde regels, maar met ruim gebruik van derogatiemogelijkheden' (door hem aangeduid als middenweg 3). De pogingen van de IASB en de FASB kunnen eerder worden gekenschetst als het door hem als middenweg 4 aangeduide 'consistente, op doelstellingen gerichte regels, zonder afkapgrenzen. Ter Hoeven kiest voor middenweg $3 \frac{1}{1} 2$ waarbij veel regels en weinig principes worden gekoppeld aan een beperkte mogelijkheid van derogatie terwijl deze derogatie uitgebreid moet worden toegelicht ('apply or explain').

In een ideale 'principles-based standard setting' omgeving is geen behoefte aan een derogatie van de regels. Immers, het is duidelijk wat de bedoeling, het 'principle', van de standaard is, dit wordt uitgebreid toegelicht in de Basis for Conclusions en de rest van de standaard is slechts richtinggevend om de onderneming te helpen bij het begrijpen van de 'principles' Aangezien echter pure 'principles-based standards' voorlopig een utopie zullen zijn, zullen accounting standards voorlopig nog (gedeeltelijk) gebaseerd zijn op 'rules'. In dat geval blijft het risico aanwezig dat een regel in een specifieke situatie op gespannen voet komt te staan met de 'principles'. Ik ben dus met Hoogendoorn en Ter Hoeven van mening dat een derogatiebepaling noodzakelijk zal zijn, maar dat we eigenlijk de kwaliteit van de standaarden kunnen afmeten aan het (niet) gebruik hoeven te maken van deze derogatiemogelijkheid. Immers, het streven moet zijn om de 'principles' zodanig helder op te schrijven dat er weinig verdere toelichting of regelgeving behoeft te worden opgesteld, waardoor het niet nodig is om de derogatiebepaling in te roepen.

Is er binnen IFRS toekomst voor 'principlesbased standards'?

In het bovenstaande heb ik getracht aan te geven dat er verschillende gradaties van 'principles-based 
standard setting' zijn, dat er voor- en nadelen kleven aan 'principles-based standard setting' in vergelijking met 'rules-based', dat IFRS op dit moment niet kan worden beschouwd als 'principles-based' en dat de ervaringen met 'principles-based' standaarden niet duiden op een onverdeeld succes. Desalniettemin moet het streven van de IASB naar meer 'principlesbased' standaarden worden ondersteund. Daarbij moet worden getracht de voordelen te benutten zonder dat de nadelen deze teniet doen. Naar mijn mening zijn daarvoor de volgende voorwaarden noodzakelijk:

- een intern consistent framework. Op dit moment kent het IFRS Framework enkele inconsistenties en wordt op bijvoorbeeld 'measurement' nauwelijks ingegaan. Het is dan vrijwel onmogelijk 'principlesbased' standaarden vanuit het Framework op te bouwen. Het huidige IASB project om het Framework te verbeteren en te vervolledigen is dan ook een welkome stap die noodzakelijk is alvorens de Board zelfs maar kan denken aan het ontwikkelen van 'principles-based standards'.

- duidelijke regels voor het opstellen van een 'principlesbased standard'. Hierbij moet worden gedacht aan afspraken omtrent de diepgang en de onderlinge verhouding tussen standaarden. Dit dient onder meer om te voorkomen de huidige gedetailleerde standaarden vervangen worden door standaarden van slechts enkele paragrafen, maar gepaard gaande met honderden pagina's implementation guidance, waardoor het effect van 'principles-based' verloren gaat.

- acceptatie van toezichthouders dat opstellers van jaarrekeningen te goeder trouw tot verschillende toepassing van een standaard kunnen komen. Indien blijkt dat toezichthouders nadere detaillering gaan aanbrengen in de 'principles-based standards' is het geheel gedoemd te mislukken omdat er grote onduidelijkheid zal bestaan omtrent de status van de standaarden, de verschillende IFRS versies en de consistentie tussen de nadere regels van de toezichthouders en de standaarden zelf.

- een sterk accountantsberoep. Alleen met een sterk accountantsberoep is het mogelijk om de naleving van 'principles-based standards' te controleren. Er is ruggengraat en vakkundige oordeelsvorming voor nodig om uitsluitend met een principe in de hand de verantwoording van een hoog gestructureerde transactie af te wijzen indien deze leidt tot een door de onderneming gewenste accounting.

- een goede 'Basis for conclusion' met duidelijk uiteengezet wat de principes zijn en hoe deze zich verhouden tot het framework en de principes in andere standaarden. Een goede uitleg van de principes maakt de acceptatie (of berusting) van zowel verschaffers als gebruikers en toezichthouders gemakkelijker.

- acceptatie door gebruikers dat er verschillen in toepassing zullen zijn tussen ondernemingen.

- acceptatie door verschaffers dat keuzemogelijkheden en uitzonderingen zullen verdwijnen en dat resultaten meer volatiel zullen worden.

Als illustratie van het laatste bulletpoint kan het volgende dienen. Op dit moment telt IAS 39 Financial Instruments: Recognition and Measurement, 45 pagina's en iets meer dan 100 paragrafen. Dat lijkt niet buitensporig veel, maar het probleem is dat het totaal aantal bladzijden aan regels omtrent IAS 39 meer dan 300 is indien we er de Application Guidance, Basis for Conclusion en Implementation Guidance bij betrekken. In het kader van 'principles-based standard setting' zou de IASB kunnen besluiten om de mogelijkheid van hedge accounting te schrappen. Dat zou ongeveer 120 pagina's van IAS 39 overbodig maken en de standaard meer in lijn met het Framework brengen zonder allerlei uitzonderingen te hoeven maken. Diegenen die roepen om meer 'principlesbased standard setting' moeten zich realiseren wat men over zich zou kunnen afroepen. Immers, niet alleen biedt 'principles-based standard setting' minder mogelijkheden om uitzonderingen en vrijstellingen te bieden, maar bovendien kan het leiden tot grotere volatiliteit van resultaat en eigen vermogen.

\section{Samenvatting en conclusies}

In dit artikel heb ik getracht aan te geven dat er verschillende invullingen zijn van het begrip 'principles-based accounting standard setting' en dat IFRS en US GAAP op dit moment aan geen van deze invullingen voldoen. Tevens is aangegeven wat de voor- en nadelen van 'principles-based standard setting' zijn en ik heb op grond daarvan enkele randvoorwaarden geformuleerd waaraan voldaan moet zijn om de invoering ervan succesvol te laten zijn. Het zal de lezer niet zijn ontgaan dat ik niet heel optimistisch ben dat binnen afzienbare termijn IFRS uitsluitend uit 'principles-based standards' bestaan. Dat wil niet zeggen dat de IASB dit niet moet nastreven, omdat het zal leiden tot een beter besef van de inhoud van 'principles' en de wijze waarop deze 'principles' consistent in meer gedetailleerde standaarden kunnen worden opgenomen, met zo weinig mogelijk uitzonderingen en zo weinig mogelijk nadere interpretaties. Verwacht mag dus wel worden dat op niet al te lange termijn de eerste vruchten zullen kunnen worden geplukt van het 'principles-based' denken binnen de 
IASB. Duidelijk is echter dat er sprake is van een continuüm, waardoor we eigenlijk beter kunnen spreken van een verbetering (of zoals de FASB het aanduidde 'objective oriented') van de wijze waarop standaarden worden opgesteld, om te voorkomen dat de indruk wordt gewekt dat standaarden in de toekomst slechts zullen bestaan uit enkele bepalingen en de rest aan het oordeel wordt overgelaten aan verschaffers en controleurs. Het blijven hanteren van de term 'principles-based' als doelstelling en tegenstelling van 'rules-based' zal eerder verwarrend zijn dan verhelderend en eerder verwachtingen wekken die niet waargemaakt kunnen worden.

\section{Literatuur}

Alexander, D. (1999), A Benchmark for the adequacy of published financial statements, Accounting and Business Research, vol. 29, no. 3, pp. 239-253.

Financial Accounting Standards Board (2002), Proposal: Principles-based approach to US standard setting, nr 1125-001, 21 Oktober 2002; zie: http://72.3.243.42/project/principles-based_approach.shtml.

Hoeven, R.L. ter (2005), Principle-based versus rule-based accounting standards: Waar ligt de balans, Maandblad voor Accountancy en Bedrijfseconomie, jg. 79, no. 10 (oktober), pp. 475-485.

Hoogendoorn, M.N. (2004), Regelgeving, principes of gedetailleerde bepalingen, in: C. Camfferman, T. Groot en F. van der Wel (red.) Tussen de regels, Liber Amicorum voor Prof. Dr J. Klaassen RA, pp. 125-144.

Institute of Chartered Accountants of Scotland (2006), Principles not rules: a question of judgement, Edinburgh; zie: http://www.iasplus.com/ europe/0603icasreport.pdf.

Nelson (2003), Behavioral evidence on the effects of principles- and rulesbased standards, Accounting Horizons, vol. 17, no. 1 (March), pp. 91-104.

Nobes, C.W. (2005), Rules-based standards and the lack of principles in accounting, Accounting Horizons, vol. 19, no. 1 (March), pp.25-34.

Schipper, K. (2003), Principles-based accounting standards, Accounting Horizons, vol. 17 no. 1 (March), pp. 61-72.

Securities and Exchange Commission (2007), Staff Observations in the Review of IFRS Financial Statements, 2 July 2007; zie: www.sec.gov/ divisions/corpfin/ifrs_staffobservations.htm.

Walker, R.G. (2007), Reporting entity concept: a case study of the failure of principles-based regulation, ABACUS, vol. 43, no. 1, pp. 49-75.

Zeff, S.A. (1978), The Rise of Economic Consequences, The Journal of Accountancy, vol. 146, no. 6 (December), pp. 56-63

\section{Noten}

1 Discussion Paper on Fair Value Measurement, IASB, 2007; zie www.iasb.org.

2 Exposure Draft Financial Reporting for Small and Medium Enterprises, IASB, 2007; zie: www.iasb.org.

3 De G4+1 bestond uit een aantal nationale standard setters die samen met de IASC (voorloper van de IASB) discussion papers opstelde. Hoewel het op dit moment bediscussieerde Leasing project van de IASB op hetzelfde principe lijkt te worden gefundeerd, wijken de tentatieve conclusies van de IASB op dit moment enigszins af van de destijds door de G4+1 gedane voorstellen. 